Article

\title{
Simulation-Based Development of a New Cylindrical-Cavity Microwave-Plasma Reactor for Diamond-Film Synthesis
}

\author{
Qijun Wang ${ }^{1,2, \dagger}$, Gai Wu ${ }^{1,2,+} \oplus$, Sheng Liu ${ }^{1,2, *}$, Zhiyin Gan ${ }^{3, *}$, Bo Yang ${ }^{3 \oplus}$ and \\ Junheng Pan ${ }^{1,2}$ (1) \\ 1 The Laboratory of Transients in Hydraulic Machinery, School of Power and Mechanical Engineering, \\ Wuhan University, Wuhan 430072, China; qj_wang@whu.edu.cn (Q.W.); wugai1988@gmail.com (G.W.); \\ peterpan@whu.edu.cn (J.P.) \\ 2 Electronic Manufacturing and Packaging Laboratory, The Institute of Technological Sciences, \\ Wuhan University, Wuhan 430072, China \\ 3 School of Mechanical Science and Engineering, Huazhong University of Science and Technology, \\ Wuhan 430074,China; yb_hust@hust.edu.cn \\ * Correspondence: victor_liu63@vip.126.com (S.L.); ganzhiyin@126.com (Z.G.); Tel.: +86-27-6877-4384 (S.L.); \\ +86-27-8754-2604 (Z.G.) \\ + The first two authors contributed equally to this paper.
}

Received: 17 May 2019; Accepted: 20 June 2019; Published: 24 June 2019

\begin{abstract}
A $2.45 \mathrm{GHz}$ microwave-plasma chemical-vapor deposition (MPCVD) reactor was designed and built in-house by collaborating with Guangdong TrueOne Semiconductor Technology Co., Ltd. A cylindrical cavity was designed as the deposition chamber and a circumferential coaxial-mode transformer located at the top of the cavity was adopted as the antenna. Two quartz-ring windows that were placed far away from the plasma and cooled by water-cooling cavity walls were used to affix the antenna to the cavity and act as a vacuum seal for the reactor, respectively. This design improved the sealing and protected the quartz windows. In addition, a numerical simulation was proposed to predict the electric-field and plasma-density distributions in the cavity. Based on the simulation results, a microwave-plasma reactor with $\mathrm{TM}_{021}$ mode was built. The leak rate of this new reactor was tested to be as low as $1 \times 10^{-8} \mathrm{~Pa} \cdot \mathrm{m}^{3} \cdot \mathrm{s}^{-1}$, and the maximal microwave power was as high as $10 \mathrm{~kW}$. Then, single-crystal diamond films were grown with the morphology and crystalline quality characterized by an optical microscope, atomic force microscope (AFM), Raman spectrometer, photoluminescence (PL) spectrometer, and high-resolution X-ray diffractometer. It was shown that the newly developed MPCVD reactor can produce diamond films with high quality and purity.
\end{abstract}

Keywords: microwave-plasma chemical-vapor deposition (MPCVD); cylindrical cavity; diamond films

\section{Introduction}

Diamond films have unique mechanical, electrical, optical, and thermal properties, and a variety of applications. In particular, the diamond is called the ultimate semiconductor material for electronic devices that may operate at high power and high frequency [1-3]. As the chemical bond of diamonds is very strong, diamond devices can work at high temperatures, as well as under strong chemical environments or in high-radiation conditions [4].

At present, there are two main methods for synthesizing diamond crystals, high-pressure high-temperature (HPHT) and chemical-vapor deposition (CVD). For the HPHT method, it is difficult to grow large single-crystal diamonds and the crystal size is mainly smaller than $10 \times 10 \mathrm{~mm}^{2}$, while the CVD method is the more promising approach to produce large-size high-quality diamond films [5]. There are three typical ways to grow CVD diamond films in the laboratory: direct-current (DC) 
arc-plasma-jet, hot-filament, and microwave-plasma CVD (MPCVD). DC arc plasma-jet technology has the advantages of a high growth rate and no electrode contamination, but the thickness of diamond films is nonuniform and the internal stress is high [6-8]. Hot-filament technology can grow large-size diamond films due to the uniform temperature distribution. However, the growth rate is relatively low and diamond films may be contaminated with impurities from the filament [9-11]. MPCVD is a promising technology and at present it is most widely used for CVD diamond growth. It is an electrodeless process, so there is no contamination from electrode materials. The collisions of electrons with gas molecules can generate ionization plasma that can contribute to the high quality of CVD diamond films [12,13].

Thus, the development of MPCVD reactors is critical for growing high-quality and large-size diamond films [14]. There have been several kinds of MPCVD reactors, such as the quartz-tube, bell-jar, tablet-quartz-window, circumferential-antenna, ellipsoidal-cavity, and multimode clamshell-cavity types, according to the shape and location of the quartz windows in the chamber [15]. Quartz-tube-type MPCVD reactors were the earliest equipment, which were only used at a low-input microwave power of less than 800 Watts and with a plasma diameter of only $25 \mathrm{~mm}$ [16]. Subsequently, bell-jar-type reactors were developed. The quartz windows would be etched and overheated once the input power was high as the plasma was very close to them. Thus, the input microwave power of the reactor was strictly limited to less than $6 \mathrm{~kW}[17,18]$. The tablet-quartz-window-type reactors employed quartz plates as microwave windows, which had a simple structure and could easily be fabricated. However, quartz windows of this type would be damaged by unwanted secondary plasma during the operation, and then cavity walls would be contaminated by $\mathrm{SiO}_{2}[19,20]$. Pleuler et al. reported on the circumferential-antenna-type reactor, which combined the advantages of a CVD system with a high efficiency and compactness. It had the potential to grow large-size diamond films with the application of bias-enhanced nucleation. Nevertheless, tuning the microwave out to be rather difficult [21]. Ellipsoidal-cavity-type reactors were first proposed by the Fraunhofer Institute [22] and could offer stable plasma with a lateral extension of about $9 \mathrm{~cm}$ diameter at a microwave power of approximately $6 \mathrm{~kW}$. However, the ellipsoidal reactor system was rather spacious and the quartz bell jar was difficult to cool [21]. Multimode clamshell-cavity-type reactors were developed by the SEKI Company and utilized as high-pressure and high-microwave power reactors, with $\mathrm{TM}_{011}$ mode (transverse magnetic mode with an axisymmetric electric field and a maximum of the electric field in the radial and axial directions, respectively) as the main excitation mode and $\mathrm{TM}_{021}$ mode (transverse magnetic mode with two maxima of the electric field in the radial direction and one maximum of the electric field in the axial direction, respectively) as the secondary mode overlapping in the cavity [15]. No quartz windows were exposed directly to plasma in the cavity and the contamination problem of the grown diamond was avoided. However, the pressure difference between the inside and outside of the deposition chamber was found to have reduced the sealing reliability [20].

In this study, a new cylindrical-cavity microwave-plasma reactor is proposed, with the expectation of achieving an outstanding sealing performance and a reliable geometric structure with little contamination from the external environment, as well as the internal quartz windows. A numerical simulation of the electric-field and plasma-density distributions is proposed to provide a feasible design for this new reactor. The performance of the developed reactor is presented for the single-crystal diamond films grown during the study. The experiment results are reported for the case with the plasma ball far away from the quartz windows and focus on the extremely high sealing ability. Therefore, the new reactor is reliable in producing high-quality and high-purity single-crystal diamonds.

\section{New Reactor Design}

In general, microwave energy in the MPCVD reactor is transmitted with a transverse electric (TE) mode via the rectangular waveguide and is converted to a transverse magnetic (TM) mode by the coaxial-mode transformer. Finally, it is coupled into the cavity through the quartz windows. The strong electric field is generated by the microwave energy transferred into the cavity and the plasma is ignited 
in a low-pressure atmosphere. Source gases are blown into the discharge area and dissociated into reactive radicals, which hit the substrate surface via atomic processes such as adsorption, desorption, diffusion, and nucleation. Diamond films are grown through these processes on the substrate at temperatures of $800-1200{ }^{\circ} \mathrm{C}$.

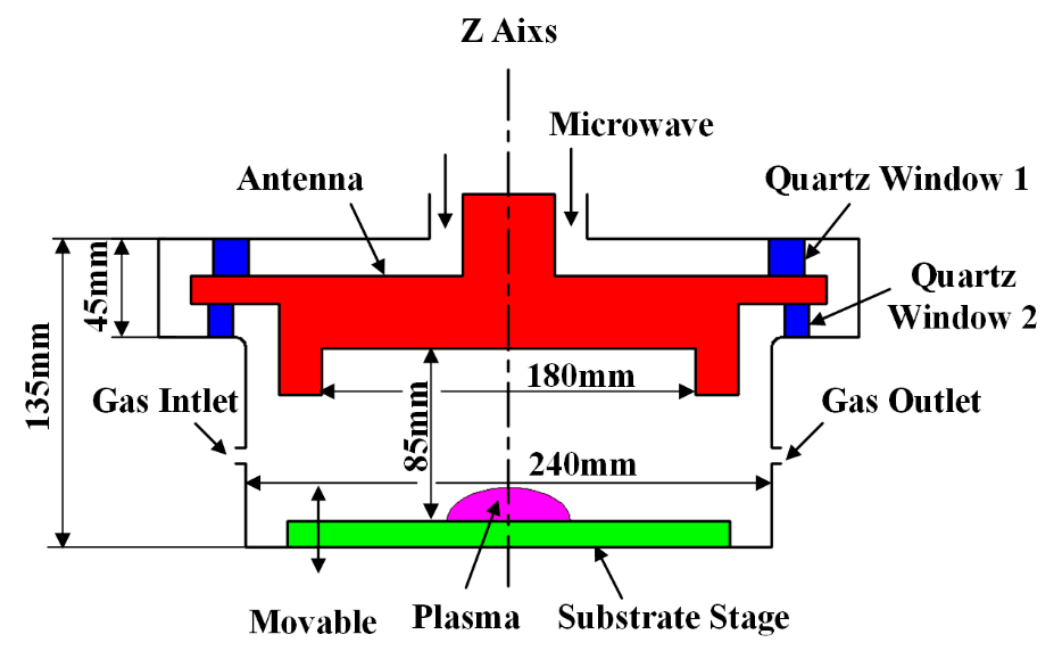

Figure 1. Schematic cross-section view of newly designed cylindrical cavity.

Figure 1 shows the cross-sectional schematic diagram of the newly developed cavity. The cavity of the reactor is composed of a cylindrical stainless-steel vacuum chamber with a volume of $4000 \mathrm{~cm}^{3}$. The inner diameter of the cylindrical cavity is $24 \mathrm{~cm}$, which is almost twice the microwave wavelength when a $2.45 \mathrm{GHz}$ microwave frequency is used. The cavity is entirely axis-symmetrical to make the distribution of microwave power into the plasma more uniform. Several ports were reserved to measure the substrate temperature and observe the plasma state during the growing process. The source gas inlet is on the left and the outlet is on the opposite side. The coaxial-mode transformer, located on the top of the cavity, was designed as a circumferential antenna. A quartz-ring window placed above the antenna was used to affix the antenna to the cylindrical cavity; the other quartz-ring window, located beneath the antenna, acted as a vacuum seal for the reactor to separate the cavity atmospheric region from the plasma-discharge region. The quartz windows, which were far away from the plasma and cooled by water-cooling cavity walls, could be effectively protected from etching and overheating from the plasma, according to this design. The sealing reliability of the reactor is provided by the pressure difference between the inside and outside of the cavity during the operation [19]. In addition, the gravity of the antenna could also enhance the sealing ability of the cavity. The bottom of the cavity was integrated with the water-cooling substrate stage, which was designed to keep the temperature of the substrate stable during the diamond-growing process. The shape of the cylindrical cavity can be changed by moving the substrate stage up and down along the longitudinal axis to make sure that the good real-time impedance-tuning function of the reactor can be realized.

\section{Numerical Simulation}

The traditional method to design an MPCVD reactor was trial and error, which was time-consuming and costly [22]. Compared to the traditional method, a numerical simulation based approach could provide a theoretical basis and efficiently improve the design process. Here, the electric-field and plasma-density distributions in the resonant cavity were simulated.

The electric fields in the cavities could be calculated by the Maxwell equations [23,24], as follows:

$$
\nabla \times\left(\frac{1}{\mu_{\mathrm{r}}}(\nabla \times \mathrm{E})\right)-\mathrm{k}_{0}^{2}\left(\varepsilon_{\mathrm{r}}-\frac{\mathrm{i} \sigma}{\omega \varepsilon_{0}}\right) \mathrm{E}=0,
$$




$$
\mathrm{k}_{0}^{2}=\omega^{2} \varepsilon_{0} \mu_{0} \text { with } \omega=2 \pi \times 2.45 \times 10^{9} \mathrm{~s}^{-1},
$$

where $\mathrm{E}$ is the electric field, $\mathrm{k}_{0}$ is the wave number of the microwave, $\omega$ is the microwave angular frequency of $2.45 \mathrm{GHz}, \sigma$ is the plasma electric conductivity, $\mu_{0}$ is the vacuum permittivity, $\mu_{\mathrm{r}}$ is the relative permittivity, $\varepsilon_{0}$ is the vacuum permeability, and $\varepsilon_{\mathrm{r}}$ is the relative permeability.

The distribution of electron density can be calculated with the following model [23,25].

$$
\nabla \times\left(-D_{e} \nabla n_{e}\right)+R_{v r} \cdot n_{e}^{2}+R_{a} \cdot n_{e}=R_{i} \cdot E^{2} \cdot n_{e}
$$

In the above equations, $D_{e}$ is the ambipolar diffusion coefficient of electrons, $n_{e}$ is the electron density, and $R_{i}, R_{v r}$, and $R_{a}$ are the ionization coefficient of hydrogen molecules, coefficient of electron disappearance, and coefficient of electron-neutral loss, respectively. Moreover, the values of $R_{i}$, $R_{v r}$, and $R_{a}$ depend on the electron energy distribution function and the reduced electric field [26]. Here, the electron disappearance coefficient of $R_{v r}$ is $1 \times 10^{-13} \mathrm{~m}^{3} / \mathrm{s}$, attachment term $R_{a} n_{e}$, can be neglected, and the value of $R_{i}$ is based on the comparison of the simulated results with the plasma distribution observed in the experiment [23].

In the simulation, the radio frequency module and plasma module of COMSOL were used to calculate the conditions of input power of $3 \mathrm{~kW}$ and gas pressure of $130 \mathrm{mbar}$. Boundary conditions for the equations were assumed as follows. The pure hydrogen discharge was assumed because it was the key factor among the reactions [12]. For solving Maxwell equations, the walls of the cavity were assumed to be a perfect conductor, except for the two quartz windows, and the tangential electric field of the walls of the cavity was set to zero. The electron densities were assumed to be zero at the boundaries.
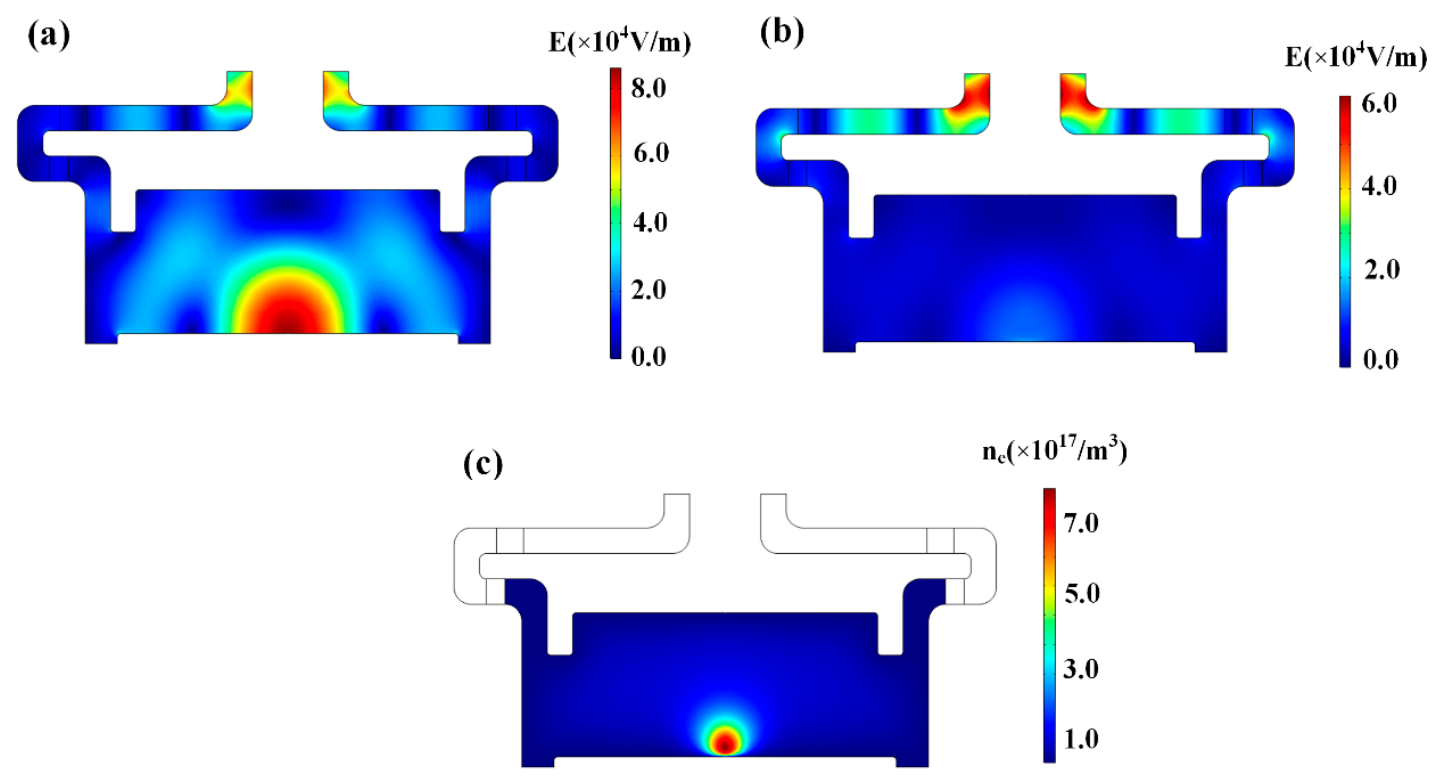

Figure 2. Simulation results of the (a) vacuum electric field, (b) microwave electric field with consideration of plasma excitation, and (c) electron-density distribution in the cylindrical cavity.

Figure 2a shows the numerical simulation results of vacuum electric-field distribution in the cavity at a microwave power of $3 \mathrm{~kW}$. It could be observed that the $\mathrm{TM}_{021}$ mode was excited within the cavity. There was a maximum-intensity area above the substrate stage with a maximum value of $8.6 \times 10^{4} \mathrm{~V} \cdot \mathrm{m}^{-1}$. The electric field and electron-density distribution with the consideration of plasma excitation are shown in Figure $2 b, c$, and the input power and reaction pressure were chosen to be $3 \mathrm{~kW}$ and 130 mbar. Electric-field intensity was found to have obviously attenuated above the substrate stage, compared to Figure 2a. A maximum value of $6.5 \times 10^{4} \mathrm{~V} \cdot \mathrm{m}^{-1}$ appeared in the inlet region of the coaxial-mode transformer. Such results could be attributed to the presence of plasma. When 
the plasma was generated, the conductivity and relative permeability of gas were changed and the intensity and distribution of the electric field in the cavity were varied as well, compared to those under its vacuum condition. Electron density is shown in Figure $2 \mathrm{c}$ and it could be seen that ball-shaped plasma appeared above the center region of the substrate stage; the diameter of the plasma was around $40 \mathrm{~mm}$, with a maximum plasma density of $7.8 \times 10^{17} \mathrm{~m}^{-3}$. No parasitic plasma appeared in the cavity. It could be indicated that the microwave energy was concentrated above the substrate stage after being coupled into the cavity by the coaxial-mode transformer. Moreover, the position of the plasma was far away from the ring-shaped quartz windows and the contamination problem introduced from quartz windows etched by plasma was solved in the newly developed reactor.

\section{Reactor Performance}

As shown in Figure 3a, the MPCVD device, named SCMP150, was manufactured collaboratively by Guangdong TrueOne Semiconductor Technology Co., Ltd (TrueOne, Foshan, Guandong, China) (www.chinasemi.net) and was automatically operated by a personal computer (PC). The reactor could work at $2.45 \mathrm{GHz}$ with a maximum power of $10 \mathrm{~kW}$. Figure $3 \mathrm{~b}$ shows the hydrogen-plasma discharge in the reactor with a microwave power of $3 \mathrm{~kW}$ and a pressure of $130 \mathrm{mbar}$. The ball-shaped purple plasma was estimated to be around $40 \mathrm{~mm}$ in diameter, which was in good agreement with the theoretically predicted value. The leak rate was tested to be as low as $1 \times 10^{-8} \mathrm{~Pa} \cdot \mathrm{m}^{3} \cdot \mathrm{s}^{-1}$, which indicated the reactor's outstanding sealing ability.
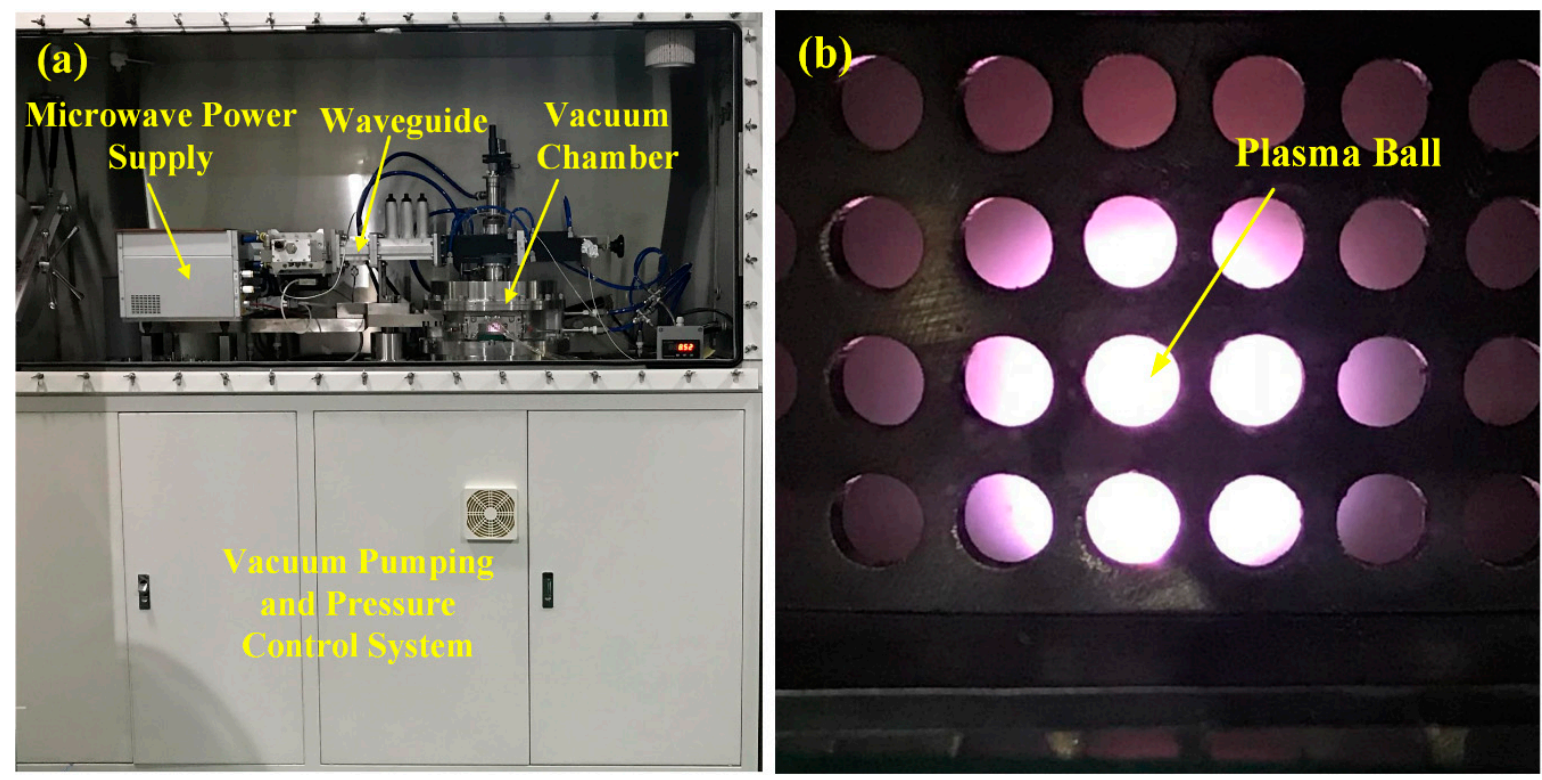

Figure 3. Photographs of the (a) newly developed reactor and (b) the hydrogen plasma discharge generated by a microwave power of $3 \mathrm{~kW}$ and a gas pressure of $130 \mathrm{mbar}$.

The experiments for the synthesis of single-crystal diamonds were performed to evaluate the built reactor. In this study, the polished (100)-oriented HPHT diamonds with a size of $4 \times 4 \times 1 \mathrm{~mm}^{3}$ were used as the substrate. They were pretreated with sulfuric acid, acetone, ethanol, and deionized water to remove metallic and organic contaminations and then nitrogen was used to dry the substrate. High-purity-grade hydrogen (99.9999\%) and methane (99.999\%) were used as the source gases and were controlled by mass flow controllers. Temperature was monitored by a two-color infrared thermometer with a value of around $1000{ }^{\circ} \mathrm{C}$ during growth. Gas-flow rate, temperature, pressure, and microwave power were automatically controlled by the operation software.

After a series of experiments, single-crystal diamond films were grown. The growth parameter, deposition rates, and crystalline quality of the diamond films are listed in Table 1. During the diamond film deposition, the microwave power was $3 \mathrm{~kW}$ and the pressure was between 130 and 155 mbar, 
respectively. The $\mathrm{CH}_{4} / \mathrm{H}_{2}$ ratio was set at between $1.5 \%$ and $3.5 \%$ and the deposition rates of the samples were in the range of 5.4-6.6 $\mu \mathrm{m} / \mathrm{h}$. The Raman full width at half maximum (FWHM) of the diamond peak was in the range of 3.1-3.5 $\mathrm{cm}^{-1}$ for Samples A, B, and C, which indicated that the diamond films were of high quality. The $\mathrm{X}$-ray diffraction (XRD) rocking curve was also used to evaluate the crystalline quality of Samples A, B, and C, with the FWHM of the diamond (400) peak ranging from 35 to 43 arcsec. Herein, with similar characteristics, Sample $C$ was chosen as an example to show the surface morphology and growth quality of the diamond films.

Table 1. Deposition conditions and growth rates of diamond films deposited by the newly designed reactor.

\begin{tabular}{cccccccc}
\hline Sample & $\begin{array}{c}\text { Power } \\
(\mathbf{k W})\end{array}$ & $\begin{array}{c}\mathrm{CH}_{\mathbf{4}} / \mathbf{H}_{\mathbf{2}} \\
\mathbf{( \% )}\end{array}$ & $\begin{array}{c}\text { Pressure } \\
(\mathbf{m b a r})\end{array}$ & $\begin{array}{c}\text { Temperature } \\
\left({ }^{\circ} \mathbf{C}\right)\end{array}$ & $\begin{array}{c}\text { Deposition Rate } \\
(\boldsymbol{\mu m} / \mathbf{h})\end{array}$ & $\begin{array}{c}\text { Raman FWHM } \\
\left(\mathbf{c m}^{\mathbf{- 1}}\right)\end{array}$ & $\begin{array}{c}\text { XRD FWHM } \\
(\mathbf{a r c s e c})\end{array}$ \\
\hline A & 3 & 1.5 & 155 & $985 \sim 1025$ & 5.6 & 3.2 & 35 \\
B & & 2.5 & 145 & $975 \sim 1015$ & 5.4 & 3.5 & 39 \\
C & & 3.5 & 130 & $925 \sim 955$ & 6.6 & 3.1 & 43 \\
\hline
\end{tabular}

Note: XRD, X-ray diffraction; FWHM, full width at half maximum.

Figure 4a shows the optical image of Sample C, grown for $14 \mathrm{~h}$ under the above conditions. As can be seen, the growth surface was macroscopically smooth and there were two hillocks near the central flat region. The formation of the hillocks was mostly related to defects originating from the substrate surface [27]. The polycrystalline diamond at the corners grew much faster than the single-crystal diamond in the central region. The higher growth rate at the corners was probably related to the local maxima of the ring-shaped distributions of $\mathrm{CH}_{3}$ concentrations [28]. The enlarged view of the flat surface is shown in Figure 4b. Growth steps were clearly observed, which suggested that the step-flow growth mode was dominated during growth under this condition.
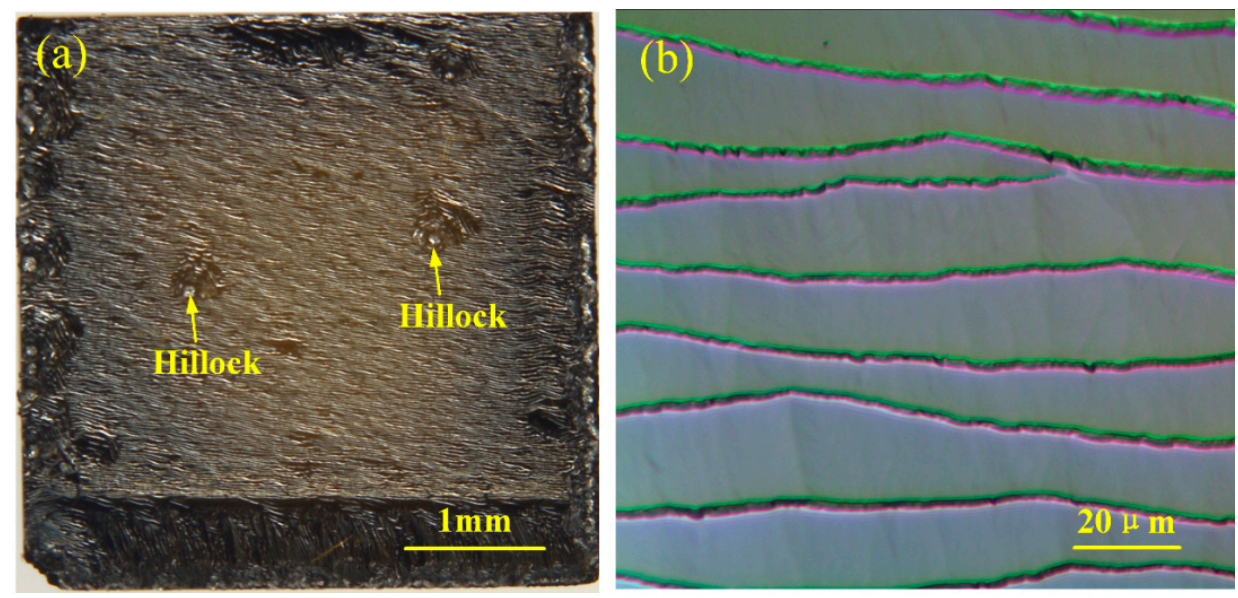

Figure 4. Optical images of Sample C. (a) Sample after growth with 15× magnification (LEICA M205 A) and (b) the surface morphology of step-flow growth with a 400× magnification (KEYENCE VHX-600).

Moreover, the morphology and roughness in the central region of $100 \times 100 \mu \mathrm{m}^{2}$ were obtained with atomic force microscopy. The images were scanned with a Bruker MultiMode 8 atomic force microscope (AFM) (Bruker, Germany) in ScanAsyst mode with SCANASYST-AIR tips. The two-dimensional image of the sample after growth is shown in Figure 5a, with the typical step-flow growth mode clearly observable, which was recognized as the growth mode for high-quality diamonds. The growth steps were found to be continuous and the bunched surface was smooth without etching pits. Root-mean-square (RMS) surface roughness was approximately $7.8 \mathrm{~nm}$. Figure $5 \mathrm{~b}$ shows the surface fluctuation along the yellow line in the AFM image. The average intervals and height from bottom to top along the terrace were about $17.5 \mu \mathrm{m}$ and $1.08 \mu \mathrm{m}$, respectively. 
(a)

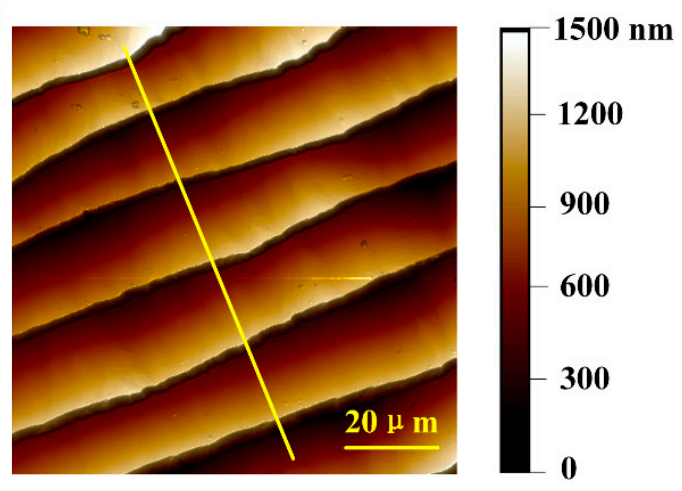

(b)

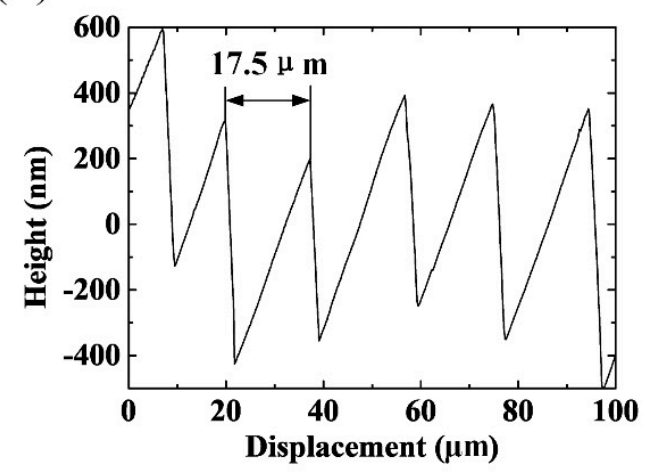

Figure 5. Atomic force microscopy (AFM) images of Sample C. (a) Two-dimensional image of the sample surface after growth and (b) surface fluctuation along the yellow line in the two-dimensional image.

Raman spectroscopy is a spectroscopic technology that is commonly used to identify diamonds, graphite, and amorphous carbon. The Raman spectra of the testing points on the sample (from Point A to Point E), measured with a RENISHAW inVia Raman spectrometer (Renishaw, Wotton-under-Edge, United Kingdom), are shown in Figure 6. Five testing points were evenly distributed from center to periphery. The Raman spectra were measured from 1200 to $1600 \mathrm{~cm}^{-1}$, excited by a He-Ne laser at $633 \mathrm{~nm}$, with a spot size of $2 \mu \mathrm{m}$. As can be seen in Figure 6, the Raman spectra of the sample only exhibited a strong diamond peak at $1332 \mathrm{~cm}^{-1}$ without any other peaks, indicating a diamond film of high purity and free of obvious carbonaceous impurities [29]. The full width at half maximum from Point A to Point E was approximately $3.0 \mathrm{~cm}^{-1}$, which revealed the uniform crystalline quality of the grown diamond film.

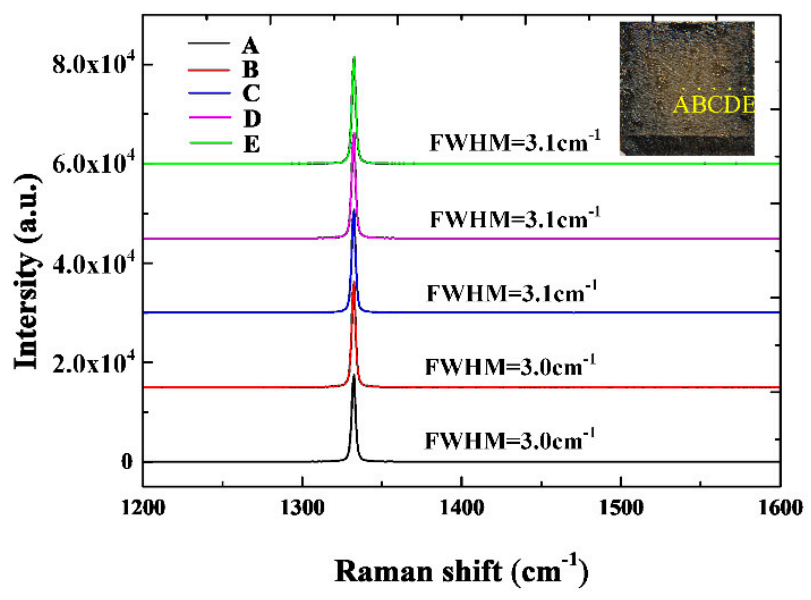

Figure 6. Raman spectra of five points evenly distributed from center to periphery on Sample C, indicating the uniformity of the diamond film. Spectra were vertically offset for clarity.

Figure 7 shows the photoluminescence (PL) spectra of Samples A, B, and C. The PL spectra of the CVD diamond films were performed with a HORIBA LabRAM HR Evolution Raman spectrometer (Jobin Yvon, France) at room temperature. The PL spectra were measured from 533 to $800 \mathrm{~nm}$, excited by a solid-state laser at $532 \mathrm{~nm}$, with a spot size of $2 \mu \mathrm{m}$. PL emissions of a nitrogen-vacancy (N-V) defect could exist in two charge states, with $(\mathrm{N}-\mathrm{V})^{0}$ centered at $575 \mathrm{~nm}$ and $(\mathrm{N}-\mathrm{V})^{-}$centered at $637 \mathrm{~nm}$, respectively. A silicon vacancy $(\mathrm{Si}-\mathrm{V})^{-}$, on the other hand, centered at $737 \mathrm{~nm}$, could be created by etching the quartz windows during CVD [19]. It was shown that the PL spectrum of the CVD diamond films grown by the newly developed MPCVD reactor was dominated by the Raman peak of the diamond centered at $573 \mathrm{~nm}$, and other PL peaks were nearly negligible. The results of the PL spectra indicated that there were very few impurities in the as-grown CVD diamond films. For these samples, 
the concentrations of nitrogen and silicon impurities were below the detection limits. The newly developed MPCVD reactor had outstanding leak-proof performance and nitrogen in the air was prevented from leaking into the reactor cavity. The quartz rings were well-protected during the diamond-growth process and were not etched by the plasma.

As shown in Figure 8, the crystalline quality of Sample C and the HPHT seed were studied with a high-resolution X-ray diffraction (PANalytical X'Pert MRD) rocking curve. The FWHM of the (400) face $X R D$ rocking curve of Sample $C$ was 43 arcsec, which is comparable to the 28 arcsec of the HPHT seed. The crystalline quality of Samples A, B, and C was also well comparable with films grown by other research groups, such as 47 arcsec reported by Mokuno et al. and 37 arcsec reported by Su et al. under similar growth parameters $[5,30]$.

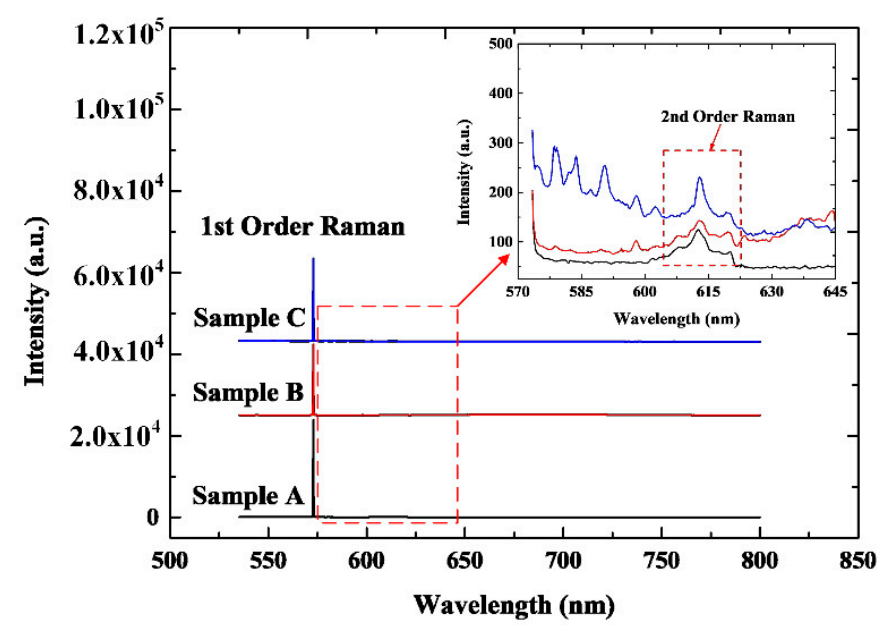

Figure 7. Photoluminescence spectra of Samples A, B, and C, indicating the high purity of the diamond films. Inset: Magnified view of area enclosed by red dashed rectangle. Spectra were vertically offset for clarity.

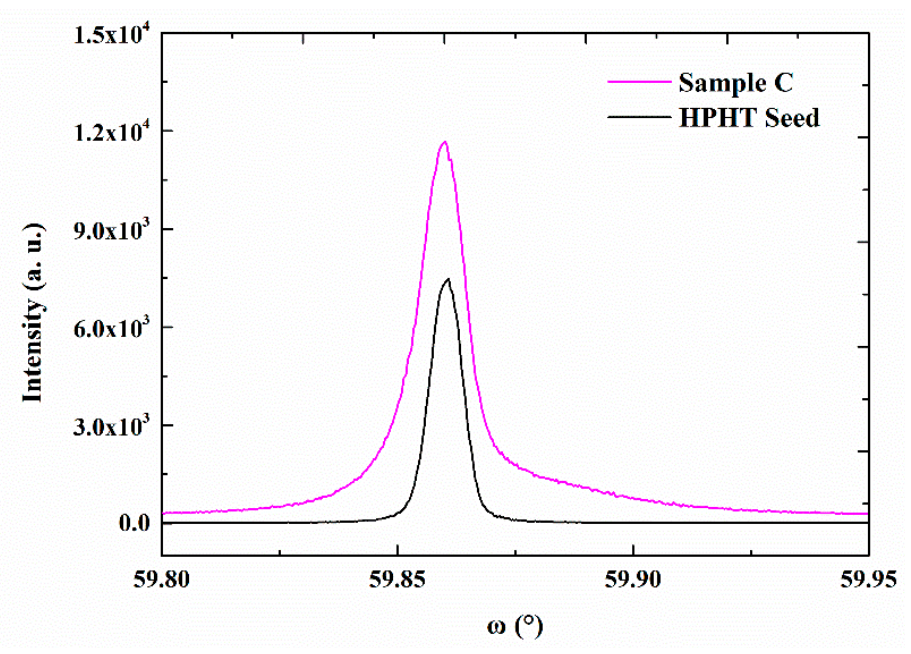

Figure 8. XRD (400) w scan of high-pressure high-temperature (HPHT) diamond seed and Sample C showing the crystalline quality of diamond film comparable to HPHT diamond seed.

\section{Conclusions}

A cylindrical-cavity-type MPCVD reactor was designed and built by analyzing the electric-field distribution and electron density in the cavity. The reactor possesses an entirely axis-symmetrical cylindrical geometry, which makes it possible for a good real-time impedance-tuning function to be realized during its operation. In addition, a circumferential antenna and quartz windows were 
proposed as its mode transformer and vacuum seal, respectively. The leak rate of the new reactor was tested to be as low as $1 \times 10^{-8} \mathrm{~Pa} \cdot \mathrm{m}^{3} \cdot \mathrm{s}^{-1}$, and the contamination problem from the external environment, as well the internal quartz windows, was effectively controlled. Experimentally, single-crystal diamond films were grown and the measurement results indicated that uniform diamond films of high quality and purity were obtained. Further research on the performance of the reactor to improve the growth rate and quality at a higher-input microwave power and pressure will be conducted.

Author Contributions: Q.W. and G.W. designed and performed the experiments. Q.W. wrote the manuscript and G.W. prepared the supplementary material. G.W., S.L., and Z.G. reviewed the manuscript. B.Y. and J.P. participated in the numerical simulation. S.L. and Z.G. supervised the project.

Funding: This research was supported by the National Natural Science Foundation of China (No. 51727901) with Sheng Liu as its PI.

Acknowledgments: The optical image of the surface after growth was taken at the Gemological Institute of China, University of Geosciences (Wuhan), China. Raman spectroscopy and atomic force microscopy were carried out at the School of Physics and Technology, Wuhan University, China. We appreciate Guangdong TrueOne Semiconductor Technology Co., Ltd. for fabricating the MPCVD equipment. We also appreciate Qiao Shen and Lei Zhang for assisting with the numerical simulation.

Conflicts of Interest: The authors declare no conflict of interest.

$\begin{array}{ll}\text { Abbreviations } \\ \text { MP } & \begin{array}{l}\text { microwave plasma } \\ \text { chemical-vapor deposition }\end{array} \\ \text { AFM } & \text { atomic force microscope } \\ \text { PL } & \text { photoluminescence } \\ \text { XRD } & \text { X-ray diffraction } \\ \text { HPHT } & \text { high-pressure high-temperature } \\ \text { DC } & \text { direct current } \\ \text { TE } & \text { transverse electric } \\ \text { TM } & \text { transverse magnetic } \\ \text { PC } & \text { personal computer } \\ \text { FWHM } & \text { full width at half maximum } \\ \text { RMS } & \text { root mean square }\end{array}$

\section{References}

1. Wort, C.J.H.; Balmer, R.S. Diamond as an electronic material. Mater. Today 2008, 11, 22-28. [CrossRef]

2. Evgeny, E.A.; Roman, A.K.; Vadim, S.S.; Andrew, A.K.; Alexander, V.K.; Viktor, G.R. Morphology of diamond layers grown on different facets of single crystal diamond substrates by a microwave plasma CVD in $\mathrm{CH}_{4}-\mathrm{H}_{2}-\mathrm{N}_{2}$ gas mixtures. Crystals 2017, 7, 166 .

3. Olsen, R.H.; Dewes, R.C.; Aspinwall, D.K. Machining of electrically conductive CVD diamond tool blanks using EDM. J. Mater. Process. Tech. 2004, 149, 627-632. [CrossRef]

4. Balmer, R.S.; Brandon, J.R.; Clewes, S.L.; Dhillon, H.K.; Dodson, J.M.; Friel, I.; Inglis, P.N.; Madgwick, T.D.; Markham, M.L.; Mollart, T.P.; et al. Chemical vapour deposition synthetic diamond: materials, technology and applications. J. Phys. Condens. Matter. 2009, 21, 364221. [CrossRef] [PubMed]

5. Mokuno, Y.; Chayahara, A.; Soda, Y.; Yamada, H.; Horino, Y.; Fujimori, N. High rate homoepitaxial growth of diamond by microwave plasma CVD with nitrogen addition. Diam. Relat. Mater. 2006, 15, 455-459. [CrossRef]

6. Railkar, T.A.; Kang, W.P.; Windischmann, H.; Malshe, A.P.; Naseem, H.A.; Davidson, J.L.; Brown, W.D. A critical review of chemical vapor-deposited (CVD) diamond for electronic applications. Crit. Rev. Solid State 2000, 25, 163-277. [CrossRef]

7. Liu, J.; Hei, L.F.; Song, J.H.; Li, C.M.; Tang, W.Z.; Chen, G.C.; Lu, F.X. High-rate homoepitaxial growth of CVD single-crystal diamond by dc arc plasma jet at blow-down (open cycle) mode. Diam. Relat. Mater. 2014, 46, 42-51. [CrossRef] 
8. Hei, L.F.; Liu, J.; Li, C.M.; Song, J.H.; Tang, W.Z.; Lu, F.X. Fabrication and characterizations of large homoepitaxial single-crystal diamond grown by DC arc plasma jet CVD. Diam. Relat. Mater. 2012, 30, 77-84. [CrossRef]

9. Zhang, T.; Wang, X.C.; Shen, B.; Shen, F.H.; Zhang, Z.M. The effect of deposition parameters on the morphology of micron diamond powders synthesized by HFCVD method. J. Cryst. Growth 2013, 372, 49-56. [CrossRef]

10. Fuentes-Fernandez, E.M.A.; Alcantar-Peña, J.J.; Lee, G.; Boulom, A.; Phan, H.; Smith, B.; Nguyen, T.; Sahoo, S.; Ruiz-Zepeda, F.; Arellano-Jimenez, M.J.; et al. Synthesis and characterization of microcrystalline diamond to ultrananocrystalline diamond films via Hot Filament Chemical Vapor Deposition for scaling to large area applications. Thin Solid Films 2016, 603, 62-68. [CrossRef]

11. Anuj Soni; Choudhary, R.K.; Polymeris, G.S.; Mishra, D.R.; Mishra, P.; Kulkarni, M.S. TL and OSL studies on undoped diamond films grown by hot filament chemical vapor deposition. J. Lumin. 2016, 177, 184-189.

12. Hideaki, Y.; Akiyoshi, C.; Yoshiaki, M.; Shikata, S. Simulation with an improved plasma model utilized to design a new structure of microwave plasma discharge for chemical vapor deposition of diamond crystals. Diam. Relat. Mater. 2008, 17, 494-497.

13. Silva, F.; Bonnin, X.; Scharpf, J.; Pasquarelli, A. Microwave analysis of PACVD diamond deposition reactor based on electric modelling. Diam. Relat. Mater. 2010, 19, 397-403. [CrossRef]

14. Gu, Y.J.; Lu, J.; Grotjohn, T.; Schuelke, T.; Asmussen, J. Microwave plasma reactor design for high pressure and high power density diamond synthesis. Diam. Relat. Mater. 2012, 24, 210-214. [CrossRef]

15. Silva, F.; Hassouni, K.; Bonin, X.; Gicquel, A. Microwave engineering of plasma-asisted CVD reactors for diamond deposition. J. Phys. Condens. Matter 2009, 21, 364202. [CrossRef] [PubMed]

16. Kamo, M.; Sato, Y.; Matsumoto, S.; Setaka, N. Diamond synthesis from gas phase in microwave plasma. J. Cryst. Growth 1983, 62, 642-644. [CrossRef]

17. Baudrillart, B.; Nave, A.S.C.; Hamann, S.; Bénédic, F.; Lombardi, G.; van Helden, J.H.; Röpcke, J.; Achard, J. Growth processes of nanocrystalline diamond films in microwave cavity and distributed co-axial mode transformer array systems: A comparative study. Diam. Relat. Mater. 2017, 71, 53-62. [CrossRef]

18. Hemawan, K.W.; Grotjohn, T.A.; Reinhard, D.K.; Asmussen, J. Improved microwave plasma cavity reactor for diamond synthesis at high pressure and high power density. Diam. Relat. Mater. 2010, 19, 1446-1452. [CrossRef]

19. Li, Y.F.; An, X.M.; Liu, X.C.; Jiang, L.; Zhang, P.W.; Guo, H.; Sun, Z.L.; Zhao, H.Z.; Tang, W.Z. A 915 MHz/75 $\mathrm{kW}$ cylindrical cavity type microwave plasma chemical vapor deposition reactor with a ladder-shaped circumferential co-axial mode transformer developed for growing large area diamond films. Diam. Relat. Mater. 2017, 78, 67-72. [CrossRef]

20. Li, Y.F.; Su, J.J.; Liu, Y.Q.; Ding, M.H.; Wang, G.; Tang, W.Z. A circumferential antenna ellipsoidal cavity type MPCVD reactor developed for diamond film deposition. Diam. Relat. Mater. 2015, 51, 24-29. [CrossRef]

21. Pleuler, E.; Wild, C.; Füner, M.; Koidl, P. The CAP-reactor, a novel microwave CVD system for diamond deposition. Diam. Relat. Mater. 2002, 11, 467-471. [CrossRef]

22. Füner, M.; Wild, C.; Koidl, P. Simulation and development of optimized microwave plasma reactors for diamond deposition. Surf. Coat. Tech. 1999, 116-119, 853-862. [CrossRef]

23. Su, J.J.; Li, Y.F.; Li, X.L.; Yao, P.L.; Liu, Y.Q.; Ding, M.H.; Tang, W.Z. A novel microwave plasma reactor with a unique structure for chemical vapor deposition of diamond films. Diam. Relat. Mater. 2014, 42, $28-32$. [CrossRef]

24. Shivkumar, G.; Tholeti, S.S.; Alrefae, M.A.; Fisher, T.S.; Alexeenko, A.A. Analysis of hydrogen plasma in a microwave plasma chemical vapor deposition reactor. J. Appl. Phys. 2016, 119, 113301. [CrossRef]

25. Hideaki, Y.; Akiyoshi, C.; Yoshiaki, M. Simplified description of microwave plasma discharge for chemical vapor deposition of diamond. J. Appl. Phys. 2007, 101, 063302.

26. Mahoney, E.J.D.; Truscott, B.S.; Mushtaq, S.; Ashfold, M.N.R.; Mankelevich, Y.A. Spatially resolved optical emission and modeling studies of microwave-activated hydrogen plasmas operating under conditions relevant for diamond chemical vapor deposition. J. Phys. Chem. A 2018, 122, 8286-8300. [CrossRef] [PubMed]

27. Achard, J.; Silva, F.; Tallaire, A.; Bonnin, X.; Lombardi, G.; Hassouni, K.; Gicquel, A. High quality MPACVD diamond single crystal growth: high microwave power density regime. J. Phys. D: Appl. Phys. 2007, 40, 6175-6188. [CrossRef] 
28. Yamada, H. Numerical simulations to study growth of single-crystal diamond by using microwave plasma chemical vapor deposition with reactive (H, C, N) species. Jpn. J. Appl. Phys. 2012, 51, 090105. [CrossRef]

29. Wu, G.; Chen, M.H.; Liao, J. The influence of recess depth and crystallographic orientation of seed sides on homoepitaxial growth of CVD single crystal diamonds. Diam. Relat. Mater. 2016, 65, 144-151. [CrossRef]

30. Shu, G.Y.; Dai, B.; Ralchenko, V.G.; Khomich, A.A.; Ashkinazi, E.E.; Bolshakov, A.P.; Bokova-Sirosh, S.N.; Liu, K.; Zhao, J.S.; Han, J.C.; et al. Epitaxial growth of mosaic diamond: Mapping of stress and defects in crystal junction with a confocal Raman spectroscopy. J. Cryst. Growth 2017, 463, 19-26. [CrossRef]

(C) 2019 by the authors. Licensee MDPI, Basel, Switzerland. This article is an open access article distributed under the terms and conditions of the Creative Commons Attribution (CC BY) license (http://creativecommons.org/licenses/by/4.0/). 